\title{
Constructing Cloud Service Platform about Jiangsu Vocational Education
}

\author{
Jing Zhou ${ }^{1, a}$, Yichun Zhang ${ }^{1, \mathrm{~b}}$ and Bin $\mathrm{Ji}^{2, \mathrm{c}^{*}}$ \\ ${ }^{1}$ Nanjing Normal University, Nanjing, P.R.China \\ ${ }^{2}$ Anhui University of Technology, Ma'anshan, P. R. China \\ a17715666526@163.com, bzhyc@njnu.edu.cn, cjibin@ahut.edu.cn \\ * The Corresponding Author
}

\begin{abstract}
Keywords: Cloud computing; Vocational education; Training; Internet+
Abstract. For constructing the cloud service platform about Jiangsu vocational education, these techniques, such as Web1.0, Web2.0, cloud software technology, remote data exchanging, were integrated into the system. Many functions, such as the school-enterprise cooperation, professional construction, regional resource platform, post training, online learning, regional big data / Internet of things and so on, were finished. By designing the "1148" cloud platform service model, a three-in-one supervisory platform included online and offline application, monitoring and management was built. The platform based on Internet+ had shown to help creating a vocational education ecosystem between teaching, learning and management modes for innovations.
\end{abstract}

\section{Introduction}

At present, cloud computing, big data, Internet of things, mobile computing and other new technologies are gradually and widely used [1]. The revolutionary impact of information technology on vocational education is becoming more and more obvious. The informationization of vocational education is now embracing major historic opportunities [2].

In order to better promote the informatization of education management, to promote the in-depth integration of information technology and vocational education, to innovate the mode of talent training, Nanjing Technical Vocational College, the Education Department of Jiangsu Province and ZTE Corporation tripartite cooperated and signed a strategic cooperation agreement. Relying on advanced technologies such as cloud computing and big data, combined with the concept of "Internet+ education", they created innovative the Jiangsu vocational education cloud service platform.

Nanjing Technical Vocational College as a cloud platform construction base to communications / network security / big data / Internet of things and other emerging national strategic areas, combined with existing professional system of the college, innovated the teaching and personnel training to enhance the school teaching and research work, promote the level of teaching, research and social service. At the same time, the use of cloud computing / big data / Internet of things and other new generation of information technology, integrated into the college information construction of smart campus to improve the campus management quality and big data scientific decision-making ability from the perspective of application-driven, data fusion and business integration.

\section{Platform Design}

The Jiangsu vocational education cloud service platform with the cloud concept of "IaaS infrastructure as a service""PaaS platform as a service""SaaS software as a service ""RaaS resource as a service" [3] is centered on the "1148" service architecture. It resolves the field of vocational education facing many hot pain points and difficult problems in practice. The "1148" service architecture shown in Fig. 1 includes 1 cloud platform, 1 cloud portal, 4 key professional directions (communication technology, network security, big data and Internet of things) and 8 application service platforms. It integrates the school-enterprise cooperation, professional construction, regional 
resource platform, post training, online learning, regional big data / Internet of things and other rich functions. The cloud platforms focus on cloud services. By establishing a unified cloud platform for all kinds of users [4], the communication and cooperation bridge between competent departments, vocational colleges and enterprises should be set up to promote innovation in teaching, learning and management modes, and finally to achieve the goal of creating a vocational education ecosystem [5].

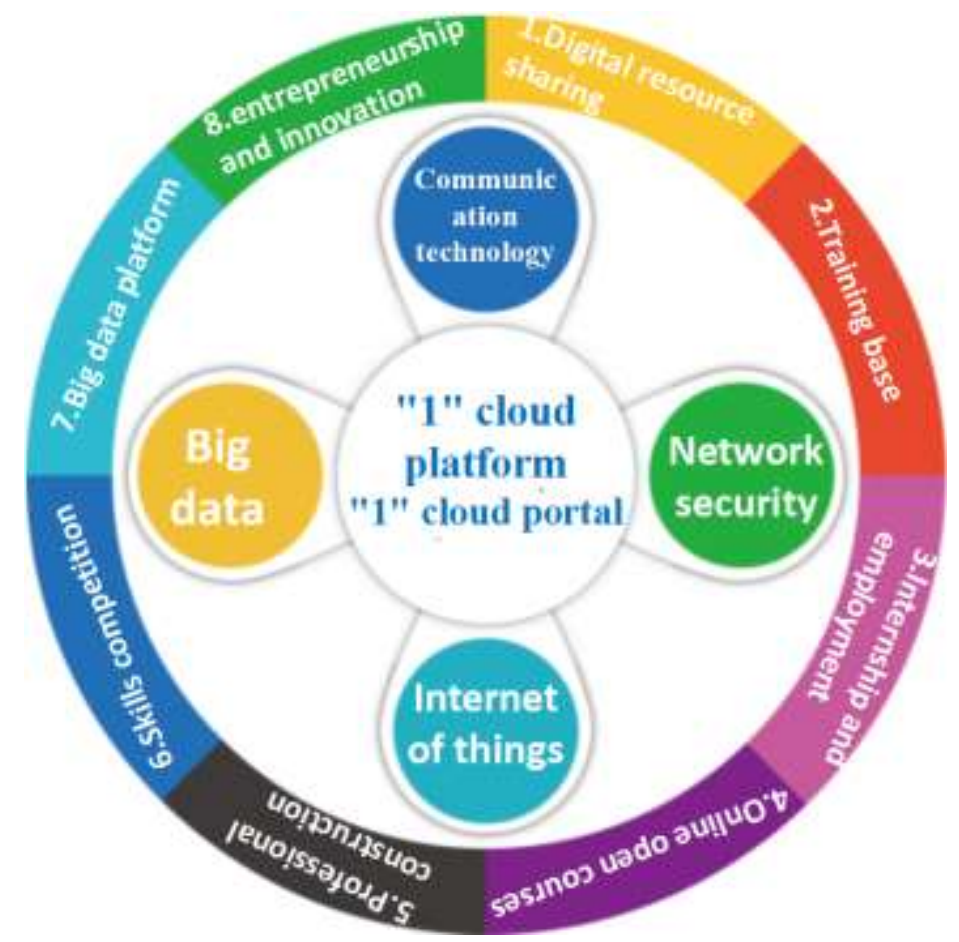

Figure 1. Jiangsu vocational education cloud platform real scene

"1" Cloud Platform. The unified cloud platform serves the vocational education system of Jiangsu Province. The hybrid cloud network of provincial-level public cloud + college-level private cloud is relatively independent but closely related.

"1" Cloud Portal. All kinds of users can understand the functions, applications and resources of the platform through the portal page of the cloud platform, meanwhile realize the uniform entrance of all platforms and all users have the same identity.

"4" Key Professional Directions. Communication technology: The cloud platform provides the latest communication courses to train the communication technology talents who are transformed from theoretical research to practical application; Network security: The cloud platform innovatively develops a training platform which serves professional construction of network security and relates skills training or competition integrating various core network security tools; Big data: The cloud platform serves the construction of big data and the integration of campus big data application, providing "decision support application service" and "campus information comprehensive service", improving campus management quality and big data science decision-making ability; Internet of things: The cloud platform provides the latest IOT and LORA practical teaching contents, and also provides a comprehensive information platform for IOT to build a green, intelligent and convenient smart campus environment to effectively improve the utilization efficiency of water, electricity, fixed assets and other resources.

"8" Application Service Platforms. Regional digital resource sharing service platform: Cloud platform provides all kinds of digital teaching materials and resources online upload and on-demand download service; Regional training base public service platform: Cloud platform provides information service system for various training bases, such as site construction, environment construction, teacher training, resource construction, teaching organization, practical training and social service, as well as comprehensive on-site training, remote training and online simulation 
services; Regional internship and employment service platform: Cloud platform establishes a bridge between regional vocational colleges, industries and enterprises, students in schools and past graduates internship and employment information services; Regional online open courses public service platform: Cloud platform aims to provide the support of the public service platform for the construction of excellent online open courses in Jiangsu province, and to provide online open course construction services for vocational colleges in the province; Internet+ professional construction service platform: Cloud platform focuses on the characteristics and needs of professional construction, online teaching, resource sharing and management of various hot spots, and the strengthening and organization of relevant applications and resources, thus forming Internet+ professional construction service platform for communication and network security and other professionals; Regional vocational skills competition public service platform: Cloud platform provides public services such as online information dissemination, information exchange, data sharing, competition training, expert consultation, online registration for teachers and students in vocational skills competition, sponsors of various competitions, contractors, expert judges, equipment manufacturers; Big data service platform: From the three dimensions of teaching employment, student service and school management, a big data environment for vocational colleges which can realize the individualized teaching, visual and predictive management, and the provision of students' comprehensive and accurate employment services is constructed; Regional student entrepreneurship and innovation service platform: Through this platform, it can realize the informatization of "maker teaching and guidance" within vocational colleges and the society, as well as the networking of entrepreneurship training, project docking, service matching and tracking guidance, etc.

\section{Application Service System}

Jiangsu vocational education cloud service platform relies on advanced technologies such as cloud computing and big data, and combines the latest research and development concept of "Internet+ education" to create "1148" service architecture. During the operation of the cloud platform, the integrated service system model was constructed based on the status of the experimental college project, including the embedded base service mode, SaaS customized service mode and online \& offline service mode.

Embedded Base Service Model. The construction of the cloud platform is shown in Fig. 2.

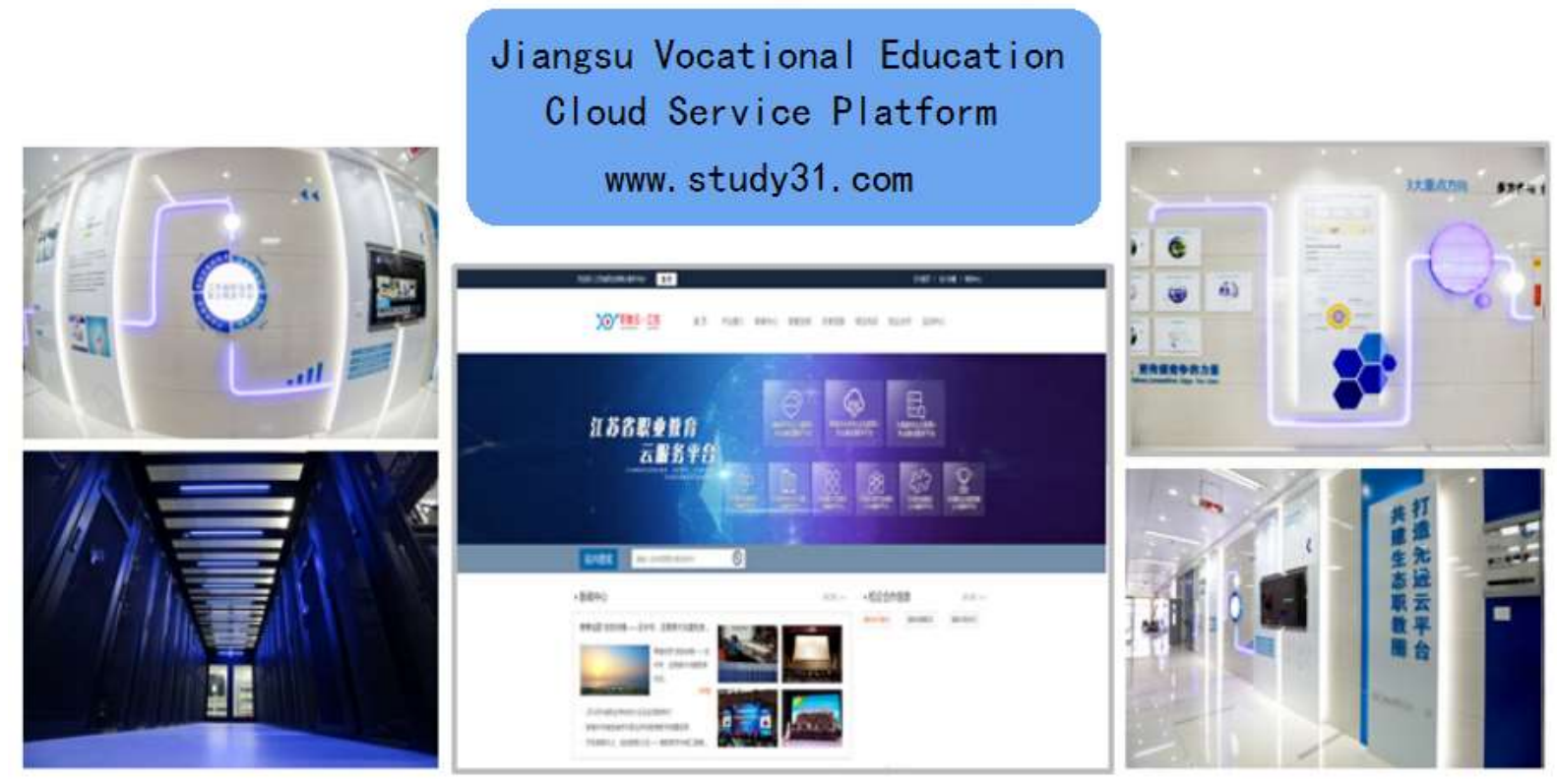

Figure 2. Jiangsu vocational education cloud platform real scene 
The base of the cloud service platform is located on the 12th floor of the electronic information building of Nanjing Technical Vocational College. The domain name is: www.study31.com. This kind of embedded base has innovated the mode of school-enterprise cooperation, and has become an excellent case of the informatization application by the ministry of education.

SaaS Customized Service Model. The cloud platform can create SaaS model customized application system for administrations, institutions, enterprises and other organizations to realize "software as a service" in the real sense [6]. The cloud shared resource pool of the cloud platform can provide Cloud sharing resources for all the SaaS application terminals of platform, while SaaS application terminal resources can also be shared on demand, to achieve a real SaaS cloud.

Online \& Offline Service Model. Based on the cloud platform, we have created an online and offline service system application model. The application of online \& offline service system is shown in Table 1 and Table 2 respectively.

Table 1 Online application service system

\begin{tabular}{|c|c|}
\hline SaaS application terminal type & Core application and functional system \\
\hline $\begin{array}{l}\text { Vocational education special } \\
\text { website terminal }\end{array}$ & $\begin{array}{l}\text { Create a portal for all kinds of construction and activity } \\
\text { projects for regional vocational education. }\end{array}$ \\
\hline $\begin{array}{l}\text { Vocational school-based } \\
\text { training terminal }\end{array}$ & $\begin{array}{l}\text { Realize the construction, management and sharing of the } \\
\text { training resources, as well as the network learning and } \\
\text { management of school-based training. }\end{array}$ \\
\hline $\begin{array}{l}\text { Teaching service and resource } \\
\text { sharing terminal }\end{array}$ & $\begin{array}{c}\text { Realize the integration of various vocational education } \\
\text { group in a SaaS services. }\end{array}$ \\
\hline $\begin{array}{l}\text { Vocational training institutions } \\
\text { network training terminal }\end{array}$ & $\begin{array}{c}\text { Provide network training system for various vocational } \\
\text { training institutions, including vocational qualification } \\
\text { certification training institutions. }\end{array}$ \\
\hline $\begin{array}{l}\text { Enterprises and institutions } \\
\text { network training terminal }\end{array}$ & $\begin{array}{l}\text { Create employee training system for various regional } \\
\text { enterprises. And the system can also be used for students } \\
\text { to employers in pre-employment and pre-job training. }\end{array}$ \\
\hline $\begin{array}{l}\text { Enterprises and institutions } \\
\text { portal terminal }\end{array}$ & $\begin{array}{c}\text { Create the enterprise portal website for all kinds of } \\
\text { regional enterprises. }\end{array}$ \\
\hline
\end{tabular}

Table 2 Offline application service system

\begin{tabular}{|c|c|}
\hline Online service & Offline service \\
\hline $\begin{array}{l}\text { Regional digital resource sharing } \\
\text { service platform }\end{array}$ & Digital resources custom open \\
\hline $\begin{array}{l}\text { Regional training base public service } \\
\text { platform }\end{array}$ & $\begin{array}{l}\text { Training digital resources custom development } \\
\text { Virtual simulation training system development } \\
\text { Relevant professional training base construction }\end{array}$ \\
\hline $\begin{array}{l}\text { Regional internship and employment } \\
\text { service platform }\end{array}$ & $\begin{array}{c}\text { Internship project matching service } \\
\text { Employment and job network training resources development }\end{array}$ \\
\hline $\begin{array}{l}\text { Regional online open courses public } \\
\text { service platform }\end{array}$ & $\begin{array}{l}\text { Excellent online open course custom development } \\
\text { Digital teaching resource package custom development }\end{array}$ \\
\hline $\begin{array}{l}\text { Internet+ professional construction } \\
\text { service platform }\end{array}$ & $\begin{array}{c}\text { Relevant professional consulting of professional de velopment, } \\
\text { digital resources development } \\
\text { Relevant professional teacher training, school-enterprise } \\
\text { cooperation docking }\end{array}$ \\
\hline $\begin{array}{l}\text { Regional vocational skills } \\
\text { competition public service platform }\end{array}$ & Skills competition network training course development \\
\hline Big data service platform & $\begin{array}{l}\text { School - oriented campus big data information service } \\
\text { Region - oriented campus big data information service }\end{array}$ \\
\hline $\begin{array}{l}\text { Regional student entrepreneurship } \\
\text { and innovation service platform }\end{array}$ & $\begin{array}{l}\text { Maker education network training course development } \\
\text { Entrepreneurship guidance network training course development }\end{array}$ \\
\hline
\end{tabular}




\section{Operation Monitoring and Management}

Vocational education cloud platform operation and maintenance system achieves a comprehensive operation, monitoring, centralized management of the college hardware and software. It provides security control functions to ensure the operation and maintenance of base security, and provides value-mining capabilities to promote continuous optimization of the cloud platform. The monitoring and management mode of cloud platform is divided into three layers as shown in Fig.3, namely monitoring layer, management layer and presentation layer.

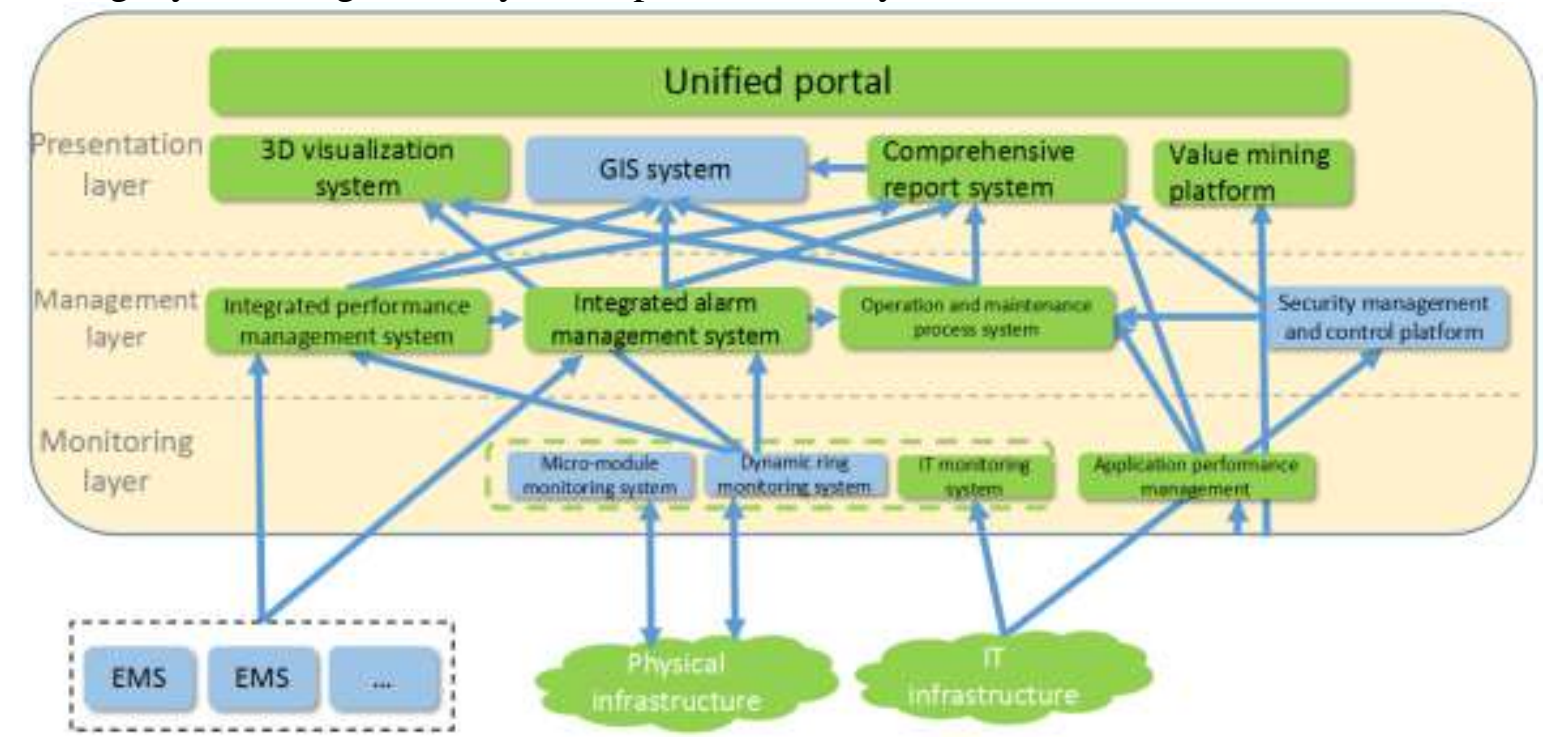

Figure 3. Cloud platform monitoring and management model

Monitoring Layer. The IT monitoring system provides a monitoring interface for IT infrastructure to monitor the operational status of IT infrastructure. The exception of IT monitoring results is passed to the integrated warning management system through the interface between the integrated alarm management. The dynamic ring monitor provides interfaces to the moving ring device in the physical infrastructure to monitor the moving ring information. The micro-module monitoring system provides interfaces to the micro-modules in the physical infrastructure to monitor the relevant information of the micro-module system, and provides PUE information to the dynamic ring monitoring system. The interface between the application management system and the vocational education cloud platform monitors the relevant indicators of cloud platform application modules and alerts while discovering the abnormalities through the interface between the operation and maintenance process management.

Management Layer. The integrated alarm management system provides the alarm collection interface for all subsystems and collects the alarm information of the whole network operation. The integrated performance management system provides the performance indicators monitoring and acquisition interface of intelligent network EMS, micro-module monitoring system, dynamic ring monitoring system and IT monitoring system. The security management and control system can connect with IT equipment to ensure the safe operation of IT equipment through standard security control scanning protocol.

Presentation Layer. The 3D visualization system provides interfaces to asset management, dynamic ring management system, micro-module management system and IT monitoring system. It collects alarm information of asset information, physical infrastructure and IT infrastructure to complete 3D rendering of these information. The comprehensive report system realizes the collection of the comprehensive report data source and the output of the comprehensive report through the interface between the various business subsystems with reporting requirements. The value mining platform realizes the value point data collection through the interface with the cloud platform application module. 


\section{Summary}

Vocational education cloud platform combined with vocational education application service demand, based on the concept of Internet +, integrated the application of Web1.0 (cloud portal), Web2.0 (various web application system), cloud software technology (various cloud SaaS services), remote data exchange technology (docking between cloud platform and digital campus), cloud software system integration technology (cloud unified authentication and data exchange) to achieve the school-enterprise cooperation, professional construction, regional resource platform, post training, online learning, regional big data / Internet of things and other rich functions.

Vocational education cloud platform combined with the existing professional system of the college to provide quality teaching resources exchange and sharing. The four professional construction resources of communication / network security / big data / Internet of things in cloud platform realized exchange and sharing by institutions. In addition, through the big data service platform, on the one hand, combined with the process data accumulated in the use of various functional modules of the cloud platform, on the other hand, combined with the comprehensive information system data of our college, based on the big data analysis, we set up an all-round supporting information system covering the whole college teaching management. It promoted the innovation of education teaching and talent training, and improved the efficiency of teaching and scientific research, as well as the level of intelligent campus management and service society.

The construction of Jiangsu vocational education cloud service platform helps to build and share digital training resources, to promote the sustainable development of resources, to reduce redundant construction, to improve resource utilization efficiency and teaching and management efficiency. Through the practical training resource cloud platform, schools, teachers and students, as well as social people can be encouraged to widely use and participate in the creation of various digital practical training resources, to create network learning environment and new educational models, so as to create broader space for the individual development of the participants. It is helpful to expand the innovative example of cloud computing in the field of practical training resources of vocational education, and provide a feasible application model for practical teaching of vocational education

\section{Acknowledgements}

This work was supported by the 2016 Key Project of Jiangsu Union Technical Institute, No.A/2016/13/001 and the grant of the Academic Natural Science Research Project of AnHui, No.KJ2017A069.

\section{References}

[1] K. Fraser, D. Gosling and M.D. Sorcinelli: New Directions for Teaching and Learning, Vol. 12 (2016) No.3, p.49.

[2] R. Qsquthorpe: Quarterly Review of Distance Education (ERIC), Vol. 4 (2015) No.3, p.227.

[3] H. Gonzalo, L. Dongman: MCS '10 Proceedings of the 1st ACM Workshop on Mobile Cloud Computing \& Services: Social Networks and Beyond, Vol. 6 (2010) No.6, p.566.

[4] J. Daniel: IEEE Data Eng, Vol. 5 (2012) No.1, p.178.

[5] L.M. Kaufman: IEEE Security \& Privacy, Vol. 7 (2011) No.4, p.61.

[6] N. Santos, K.P. Gummadi and R. Rodrigues: Hot Topics in Cloud Computing, Vol. 11 (2012) No.1, p.332. 